\title{
Effects of avatar character performances in virtual reality dramas used for teachers' education
}

\author{
Pyoung Won Kim ${ }^{a^{*}}$, Yang Sook Shin ${ }^{\text {b }}$, Byoung Hoon $\mathrm{Ha}^{\mathrm{c}}$ and Marco Anisetti ${ }^{\mathbf{d}}$
}

\footnotetext{
${ }^{\mathbf{a}}$ Department of Korean Language Education, Incheon National University, Incheon, Republic of Korea; ${ }^{\mathbf{b}}$ Department of English Language Education, Incheon National University, Republic of Korea; ${ }^{\mathrm{C}}$ Department of Performing Arts, Incheon National University, Republic of Korea; ${ }^{\text {d }}$ Dipartimento di Informatica, Universit`a degli Studi di Milano
}

Virtual reality drama has the benefit of enhancing immersion, which was lacking in original e-learning systems. Moreover, dangerous and expensive educational content can be replaced by stimulating users' interest. In this study, we investigate the effects of avatar performance in virtual reality drama. The hypothesis that the psychical distance between virtual characters and their viewers changes according to the size of video shots is tested with an autonomic nervous system function test. Eighty-four college students were randomly assigned to three groups. Virtual reality drama is used to train teachers concerning school bullying prevention and, deals with the dialogue between teachers and students. Group 1 was provided with full shot video clips, Group 2 was shown various clips from full shots to extreme close ups, and Group 3 was provided with close-up shots. We found that the virtual reality drama viewers' levels of stimulation changed in relation to the size of the shots. The R-R intervals of the electrocardiograms (ECG, bio-signal feedback) became significantly narrower as the shot size became smaller.

Keywords; Virtual reality; virtual reality drama; video shot size; electrocardiogram (ECG); bio-signal feedback; teacher education;

*Corresponding author. Email: pwkim@inu.ac.kr

\section{Introduction}

Currently, virtual reality is actively used in e-Learning or in the field of teachers' education. Educational department students are able to train using mock students in simulated situations in virtual drama classrooms. The effects of avatar characters' demonstrations in virtual worlds have 


\section{The effects of avatars' appearance in virtual Reality Drama}

a crucial influence on people as well as on social communication in the real world (Banakou (2010)). Virtual reality drama has the benefit of enhancing immersion, which was lacking in original e-learning systems (Andrea (2009)). Dangerous and expensive educational content can be replaced by stimulating users' interests. In this study, we investigate the effects of avatar performances in virtual reality dramas.

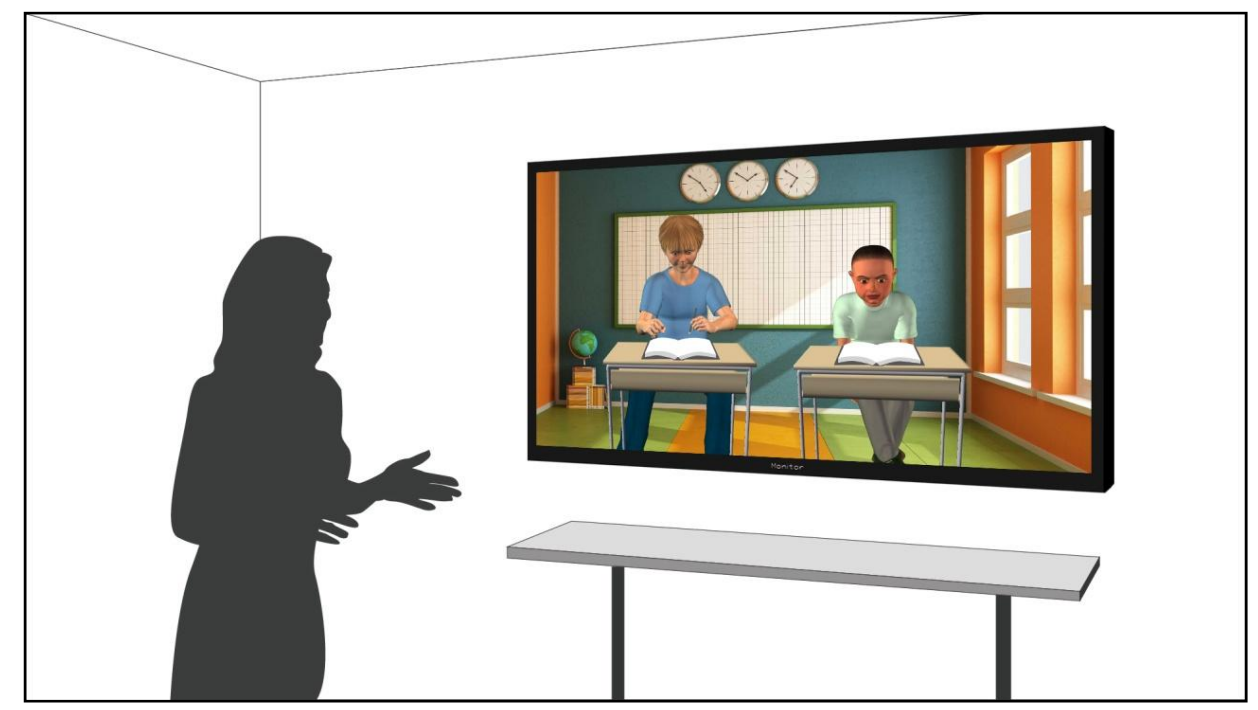

Figure 1. virtual reality simulated situations for teacher Education.

In plays, the audience decides the direction of their gaze and the field of view for themselves; however, in screen dramas they have no choice but to follow the view the director composes. Therefore, the director controls the production, expecting the viewers to recognize the vision he intended. Zettle provides a manual that shows how to apply major aesthetic elements to manipulate people's perception (Zettle (1998)). The director constructs scenes with the aesthetic foundation that comes from his experience, but often this basis cannot be explained clearly. This is related to the lack of a basis for objectively judging the viewers' accommodation of the scenes. Previous studies on television viewers' levels of stimulation while controlling different variables theorize on this basis (Mattes (1982); Lang (2000); Angelini (2008)).

There are several methods of assessing viewers' levels of stimulation: observation of behavior, self-reporting, measurement of biofeedback, or interviewing subjects. Bio-signals tracked with electroencephalograms, electrocardiography, functional magnetic resonance imaging, or blood pressure monitoring can reflect objective findings. 


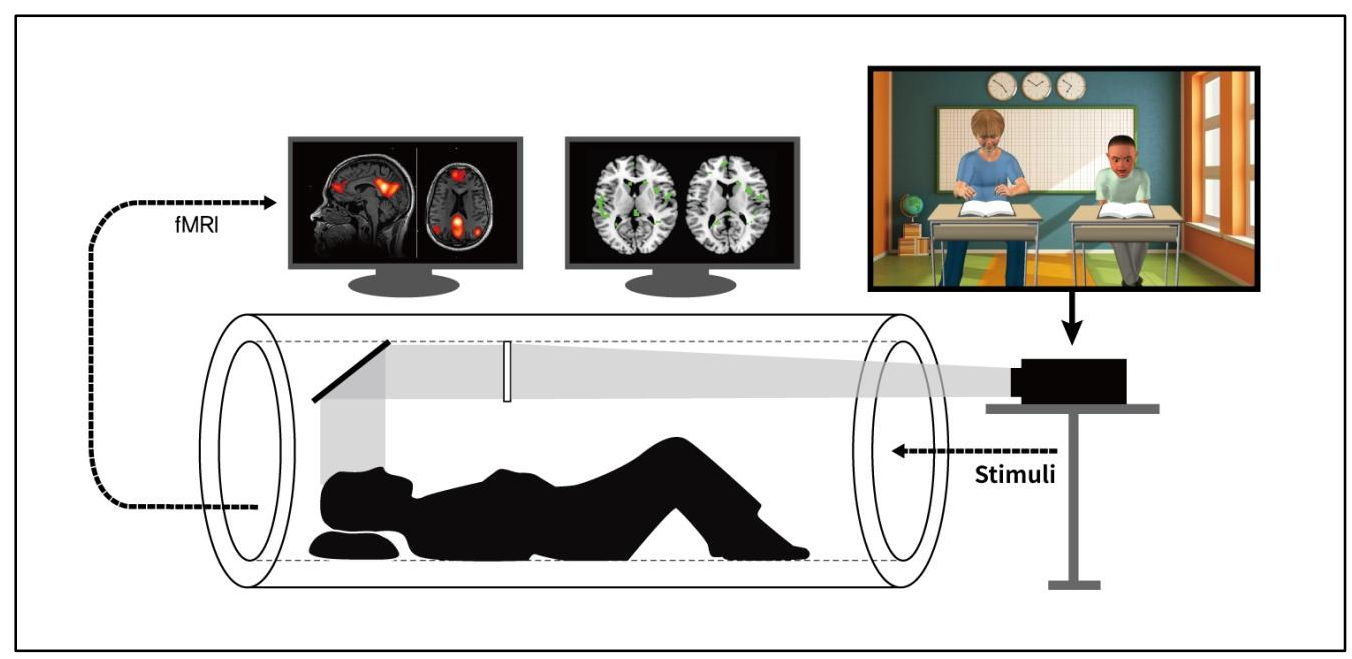

Figure 2. Brain activity was measured using functional magnetic (fMRI)

Bio-signals have mostly been extensively investigated in the fields of physiology and engineering. Stimulation is associated with physiological changes, such as an increase in heart rate, perspiration, muscle tension, or rapid respiration (Barlow (2001)). As stimulation heightens, sympathetic discharge in the nervous system is activated. As the blood supply to the heart increases, blood flow in the digestive system decreases resulting in diarrhea or constipation (Fox (2008)). Arousal influences the autonomic nervous system (ANS) and is associated with physiological changes in the body (Figure 3).

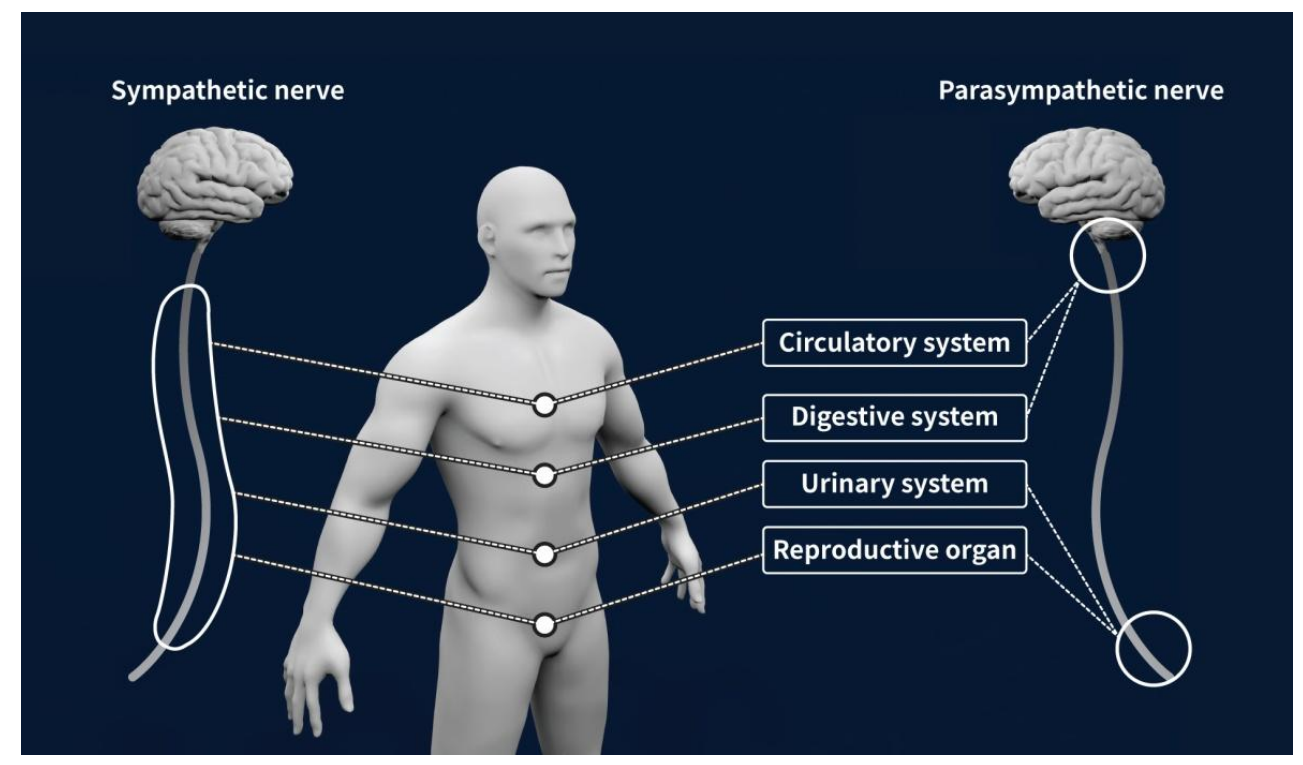

Figure 3. The autonomic nervous system (ANS) 


\section{The effects of avatars' appearance in virtual Reality Drama}

Those responses enable stimulation to be expressed in specific bio-signals, as well as in signals that reflect the index of stimulation. In the areas of broadcasting and communication, the methods measuring a heart rate or a skin conductance are generally used (Ravaja (2004); Lang (2005)) as well as facial expression changes captured using video analysis (Andreoni (2006)). For instance, facial expression changes as reaction to a specific stimulus (e.g., codified as Facial Action Coding System FACS (Ekman (1997))) allows to infer the emotional feeling of a given subject (Anisetti (2009); Ghanem (2013)).

An electrocardiogram (ECG) records the periodic electrical activity of the heart. Clinically, ECGs are used to detect wave abnormalities that indicate cardiac dysfunction. For example, QRS reflects ventricular contraction when blood is pumping out of the ventricle into the aorta. The "ST segment," which is between the QRS and T waves, is depressed in patients with angina (Garcia (2009)). In addition to the clinical use of wave abnormalities, the variability in $\mathrm{R}-\mathrm{R}$ intervals has been demonstrated to provide a heart rate calculation. The $\mathrm{R}-\mathrm{R}$ interval is the time elapse between two consecutive R waves in an electrocardiogram (Figure 4).

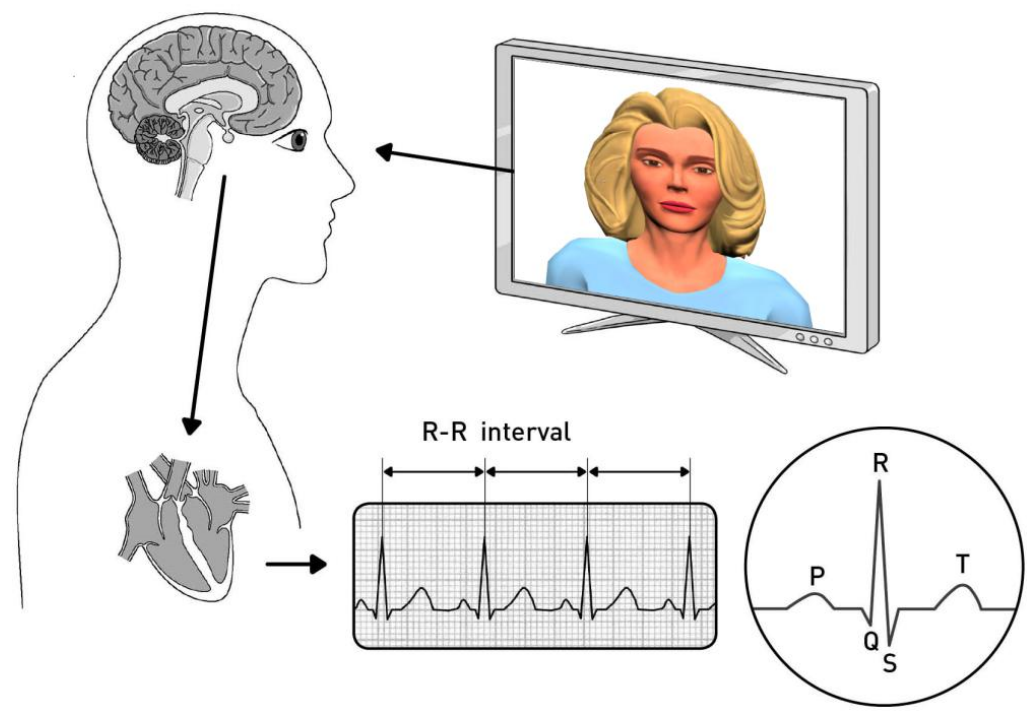

Figure 4. measuring changes in viewers' physiological state.

An ECG provides electrophysiological data in a time-dependent manner with factors composed of electrical waves. In order to select appropriate data for this study, we attempted to 


\section{The effects of avatars' appearance in virtual Reality Drama}

determine the degree of virtual reality drama viewers' stimulation by focusing on the analysis of $\mathrm{R}-\mathrm{R}$ intervals, rather than centering on spectra or times-series analysis. Such an approach can provide sympathetic monitoring of the body, resulting in an interpretation of the ANS that expresses the stimulation status (Yang (2009); Sinji ( 2004)).1 The remainder of this paper is structured as follows. Section 2 underlines the research hypotheses. Section 3 presents our experimental methodology describing the subjects, the protocol adopted and the materials used for the experimentation. Section 4 discusses the experimental results analyzing the acquired data. Section 5 presents our results while Section 6 draws our conclusions.

\section{Research hypotheses}

The size of a shot means how far or close we perceive an object or a person appearing on screen to be (Zettl (1998)). In other words, it is not merely a matter of placing an object of a certain size, it also delivers the circumstances of the frame that the object is in. The long shot, exposing a broad range, is used as an establishing shot, which shows the place and time as well as the relationship of the location to the objects. Compared with the long shot, the full shot gives an opportunity to recognize, to some degree, the character of a person along with spatial information. The medium shot focuses more on the character of the person by explaining a circumstance, but it still gives information on the space and other characters (Figure 5).
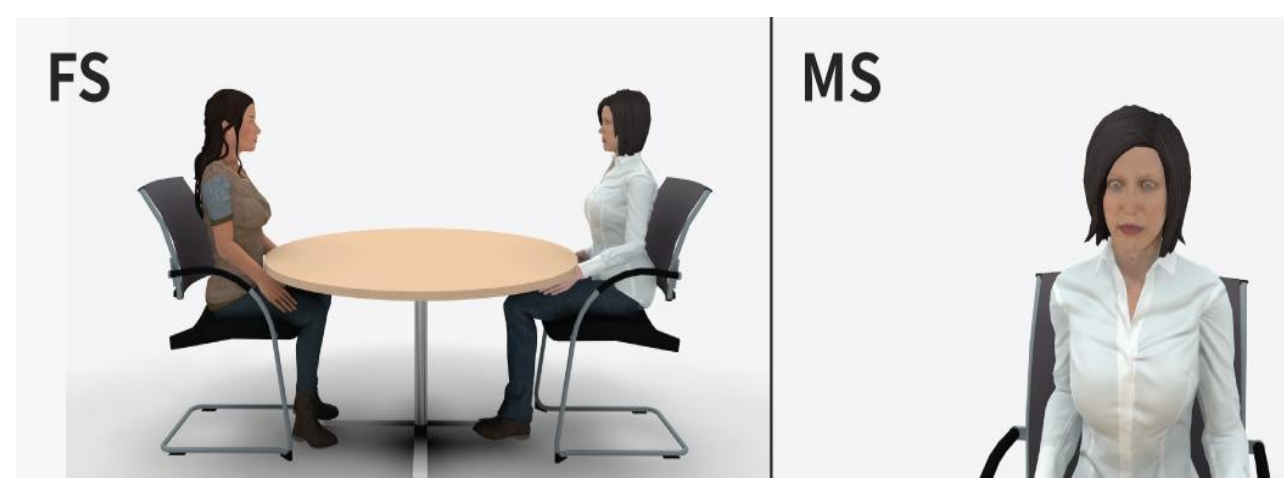

Figure 5. The full shot and The medium shot

\footnotetext{
${ }^{1}$ A heart rate is defined as beats per minute and corresponds to the number of the R-R interval per minute. Measuring R-R intervals has an advantage of monitoring the dynamic emotional state instantly compared to measuring the heart rate, which estimates the average number of $\mathrm{R}-\mathrm{R}$ intervals per minute.
} 


\section{The effects of avatars' appearance in virtual Reality Drama}

However, the medium close-up shot (bust shot) and the close-up shot are appropriate when describing specific details (Figure 6),, such as facial expressions, while excluding spatial information (Arijon (1976); Monaco (1981); Millerson (1985); Bordwell (1993)). In movies and dramas, the classification of these shots is more delicately defined and used with the consideration of the flow of emotions. In generally, the definition methods for shots are classified according to how much focus is rendered on a character, while the standard for close-up shots differs from country to country (Zettl (1998)).
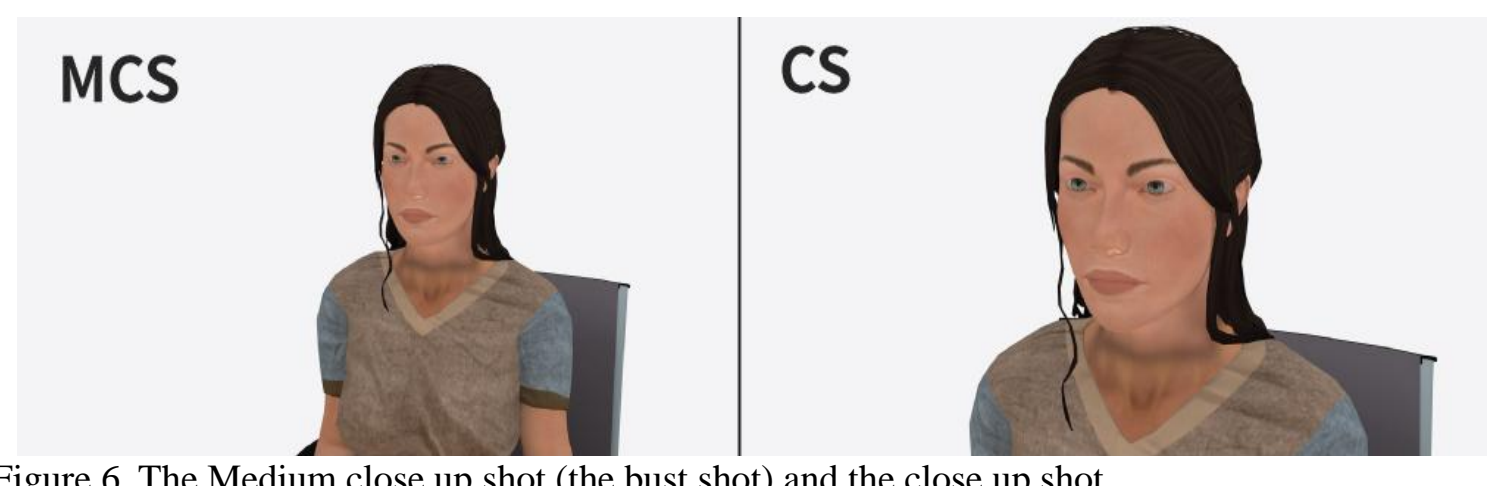

Figure 6. The Medium close up shot (the bust shot) and the close up shot

In this study, the hypothesis that the psychical distance between characters and viewers can be changed according to the size of shots is confirmed by an ANS function test. A real time biosignal measurement was applied to analyze the phenomenon of media accommodation. The measurement of $\mathrm{R}-\mathrm{R}$ intervals from electrocardiograms was carefully used when analyzing viewers' levels of stimulation. The hypotheses of this study are as follows:

H1: The response of a viewer's ANS is significantly different according to the size of the shot.

H2: The self-reporting method of viewers' levels of stimulation and the ANS function test will show a difference.

H3: The response of viewers' ANS will vary between male and female according to the size of the shot.

H4: The response of the ANS will be different according to the scenes from a virtual reality drama. 


\section{The effects of avatars' appearance in virtual Reality Drama}

\section{Method}

\subsection{Subjects}

Eighty-four university students (42 males, 42 females) took part in this experiment $(\mu=22.6$ years old, $\sigma=2.66$, range $=17-28$ ). Electrocardiogram measurements were taken while they listened to classical music or watched video clips for $10 \mathrm{~min}$ in return for a free meal pass. They were randomly divided into three groups $(n=28,29,27)$. The difference in the sample size from the original sample was due to the fact that in the beginning each of the three groups comprised 30 students, i.e., a total of 90 participants, but six students were excluded from the experiment because of clinical abnormalities revealed by their electrocardiograms. All subjects participated voluntarily and signed consent forms.

\subsection{Experimental Protocol}

The overall study design was a randomized control group. In line with the hypothesis, the subjects were divided into three groups. This was meant to control the carryover effect, which brought disadvantages within the subject design. Electrocardiograms were measured after the participants listened to the same stimulus - classical music. More electrocardiograms were then measured while each group was shown virtual reality drama video clips of the same content but with different shot sizes (Figure 7).

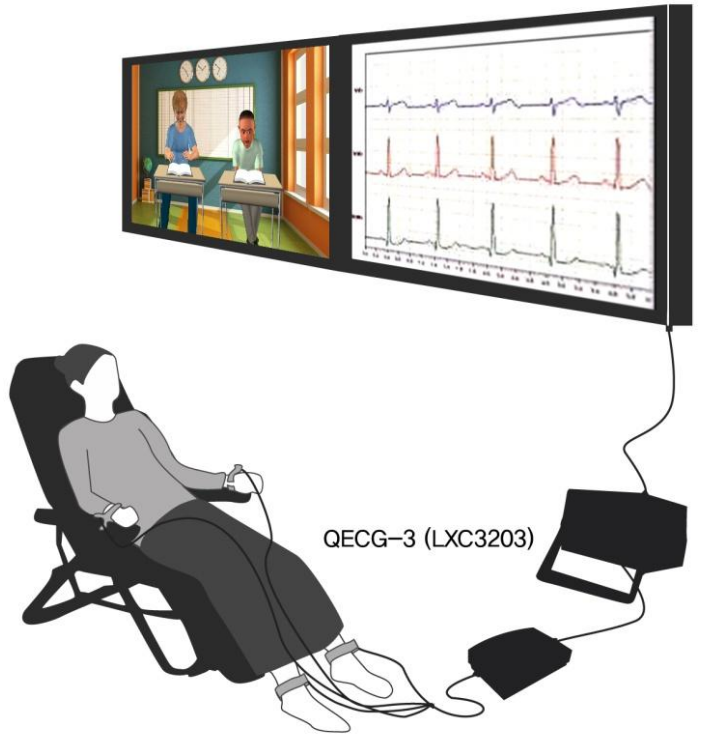

Figure 7. Measuring ECG changes in viewers' physiological state. 


\section{The effects of avatars' appearance in virtual Reality Drama}

After measurement, the checklists evaluating the level of the participants' stimulation were collected. Protocols for the procedure were in compliance with the guidelines set by the institutional review committee of KoNIBP (Korea National Institute for Bioethics Policy).

\subsection{Stimulus Materials}

To generate stimulation, the subjects were shown virtual reality drama productions. These were created using StoryBoard Artist 7 (storyboard software, U.S.A), and were based on scenes from School 2013-a drama, a Korean Broadcasting System production. This series focuses on portraying the concerns, struggles, and dilemmas of today's youth. It is a story about Seungri High, a troublesome school that houses students from the most eligible to the most problematic. School 2013 shows the different life stories of teachers and students as they emerge from conflicts and compromises. As the university students had varied interests and background knowledge, episodes based on a school allowed the control of the content variables and enabled the participants to relate to the characters. After a preliminary survey, four scenes that evoked the most sympathy out of the all scenes containing teacher student conflicts were chosen for study. The selected four scenes were evenly allotted to both genders (Table 1). Twenty-three pretest subjects who did not participate in the study evaluated all the scenes. The selected scenes were similar to the teacher student conflicts depicted in the American drama series Glee (2009) and Awkward. (2011). (See Appendix.)

Table 1. The content of stimulus materials

\begin{tabular}{c|c}
\hline Scene & Contents \\
\hline Scene 1 & Conflict between a female student and a male teacher concerning the teacher's academic guidance \\
\hline Scene 2 & Conflict between a male student and a male teacher concerning the teacher's school guidance \\
\hline Scene 3 & Conflict between a female student and a female teacher concerning the teacher's academic guidance \\
\hline Scene 4 & Conflict between a male student and a female teacher concerning the teacher's school guidance \\
\hline
\end{tabular}

To produce the selected scenes in three versions with different shot sizes, four professional actors practiced for two weeks then the scenes were filmed in a studio. The actors consented to their pictures and videos being used for research purposes. The first video (Source 1 in Figure 3) was filmed and edited in fullshot. The second video (Source 2 in Figure 3) was filmed in full 
shot at the beginning, cross filmed, and then finished with an extreme close-up. In the third video (Source 3 in Figure 3), only the first scene, which was the establishing shot, was filmed in full shot, and the rest was cross filmed in close-up until the end.

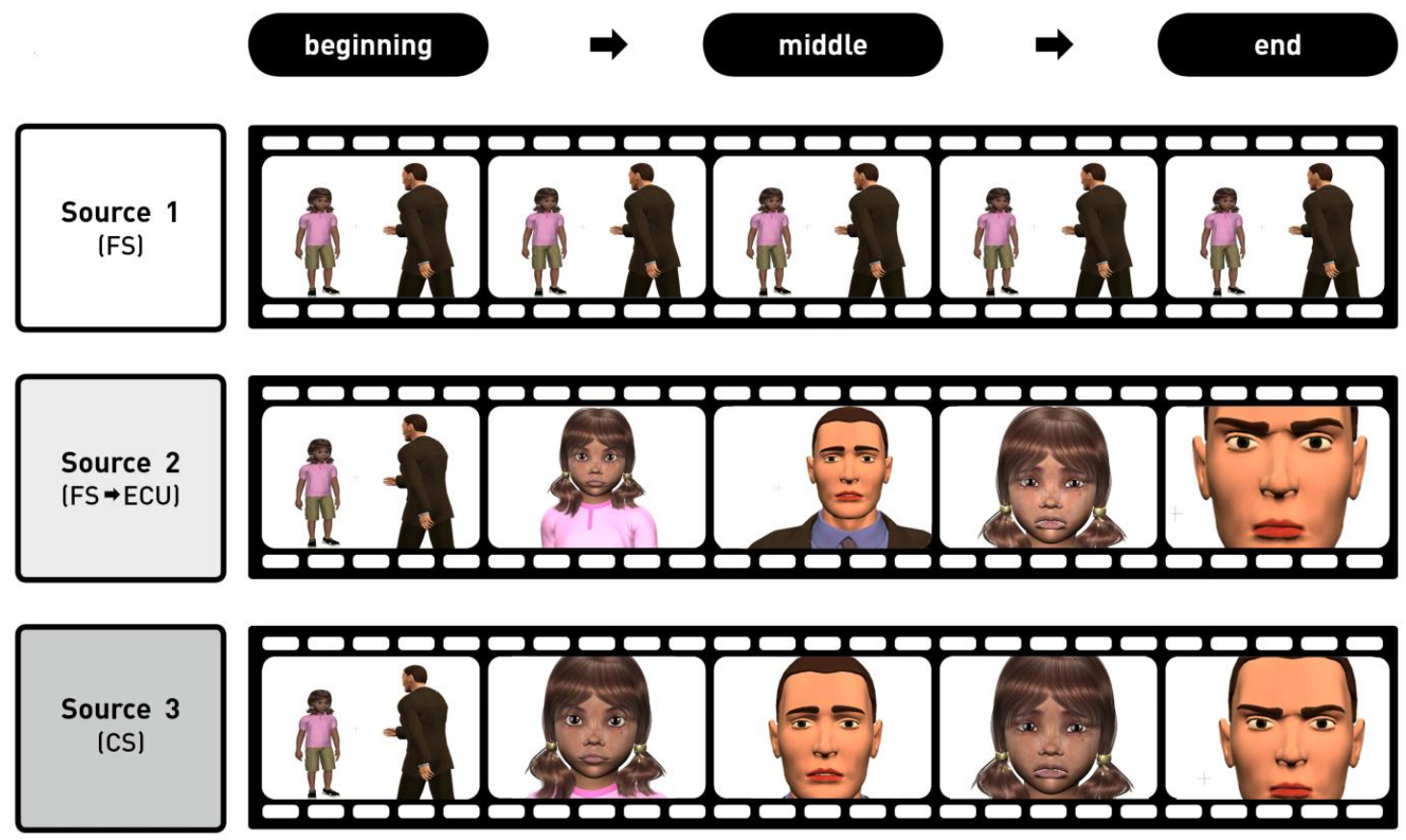

Figure 8. Three versions with different shot sizes

\section{Measurement and Data Analysis}

\subsection{ECG Data Collection}

For the ECG analysis, a QECG-3 ${ }^{\circledR}$ (Quantitative Electrocardiography-three Limb Lead, LXC $3203^{\circledR}$, Daejeon, Korea) model was used. The standard three limb leads (Lead I, Lead II, and Lead III) were applied according to the manufacturer's recommendation. The subjects were asked to sit. While in a resting state, they listened to classical music for $5 \mathrm{~min}$, then watched four video scenes for 5 min while the ECG electrode sensors were attached. Real time ECG values were monitored and displayed by this system.

\subsection{Assessment of Stimulation Levels}

After ECG data collection, the subjects were given a checklist for self-reporting the level of effect the characters had on them. The subjects were asked to record the level of effect that the 


\section{The effects of avatars' appearance in virtual Reality Drama}

male and female students, and male and female teachers had on them, on a scale from 1 (not agitated at all) to 10 (extremely agitated).

\subsection{R-R Interval Profile (Tachogram) Analysis durlqnxj}

Stimulation levels were evaluated using the mean values of the R-R interval variability. When the ECG data was converted into a graph that showed the changes in the R-R interval, the R-R interval profile ( $R-R$ interval tachogram) could be displayed. Shortening of the R-R interval could be interpreted as the activation of sympathetic activity. It was also associated with the person immersed in the drama being in an excited state (Figure 9a). In contrast, a longer R-R interval represented the activation of parasympathetic activity and was associated with a relaxed condition (Figure 9b).

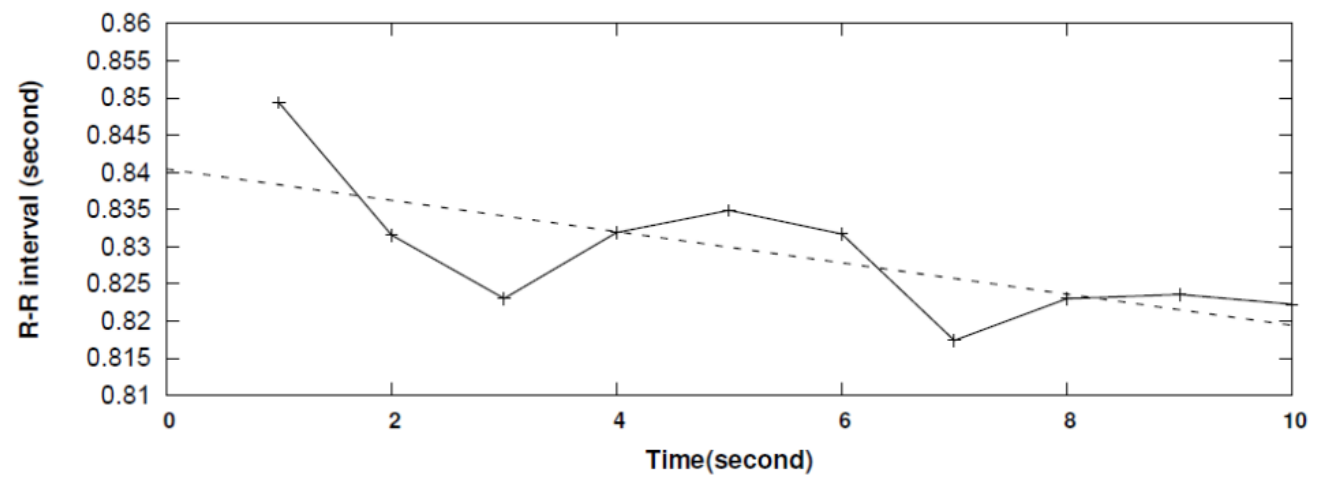

(a)

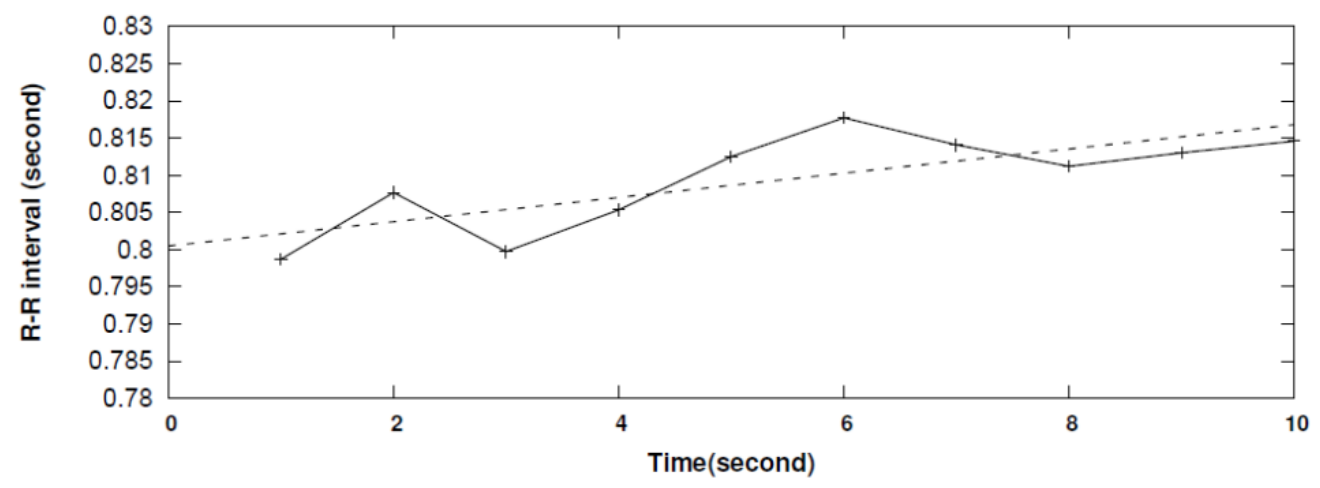

(b)

Figure 9. R-R interval profile (Time-Series Plot, tachogram). Linear regression line (dotted) underlining the trend. 


\section{The effects of avatars' appearance in virtual Reality Drama}

\subsection{Statistical Analysis}

The mean values of the R-R interval that changed in seconds were constructed for the GLM (General Linear Model) repeated measures procedure. The baseline characteristics of the three groups were compared using one-way ANOVAs and independent t-tests. The effects were statistically analyzed by comparing the mean of the R-R intervals with the repeated measures ANOVAs. To measure the effect size, an $\eta^{2}$ was used. A p-value below 0.05 was considered to indicate statistical significance.

\section{Results}

\subsection{Pretest Homogeneity}

First, to confirm that there was no significant difference among the groups on the same stimulus, an ANOVA was performed on the R-R interval while subjects were listening to classical music. As a result, there was no significant difference in R-R intervals among the three groups (Group 1 [n $=28, \mu=0.7984, \sigma=0.060]$, Group $2[\mathrm{n}=29, \mu=0.7858, \sigma=0.738]$, Group $3[\mathrm{n}=27, \mu=0.7924, \sigma=0.141]$ ) (Table 3).

Table 2. Comparison of Baseline among the three groups

\begin{tabular}{lcccccc}
\hline Stimulus & Source & SS & $d f$ & MS & F & $p$-value \\
\hline \multirow{2}{*}{ Classical } & Between & 0.003 & 2 & 0.001 & 0.154 & 0.857 \\
music & Within & 0.771 & 81 & 0.01 & & \\
& Total & 0.774 & 83 & & & \\
\hline
\end{tabular}

Table 3. Comparison of Baseline between males and females

\begin{tabular}{lccccccc}
\hline Stimulus & Group & Sex & $n$ & $\mu$ & $\sigma$ & $t$ & $p$-value \\
\hline \multirow{4}{*}{$\begin{array}{l}\text { Classical } \\
\text { music }\end{array}$} & Group 1 & male & 16 & 0.8027 & 0.06897 & \multirow{2}{*}{0.636} & \multirow{2}{*}{0.53} \\
\cline { 2 - 8 } & Group 2 & male & 15 & 0.7827 & 0.07455 & \multirow{2}{*}{0.227} & \multirow{2}{*}{0.822} \\
\cline { 2 - 8 } & $(n=29)$ & female & 14 & 0.7891 & 0.07584 & & \\
& Group 3 & male & 11 & 0.8104 & 0.11559 & \multirow{2}{*}{0.848} & \multirow{2}{*}{0.404} \\
& $(n=27)$ & female & 17 & 0.7632 & 0.15753 & & \\
\hline
\end{tabular}

\subsection{Assessment of the Characters' Levels of Stimulation}

Figure 10 assesses the subjects' levels of stimulation after watching the Virtual Reality drama 
video clips. The tendency of evaluating the stimulation effects of the characters was consistent in Group 1, which was shown video clips filmed in full shots; Group 2, which was shown video clips filmed in various shots; and Group 3, which was shown video clips recorded in close-up shots. However, the difference among the groups in four characters was not statistically significant (Table 4). There was no significant difference between males and females within the groups (Table 5).

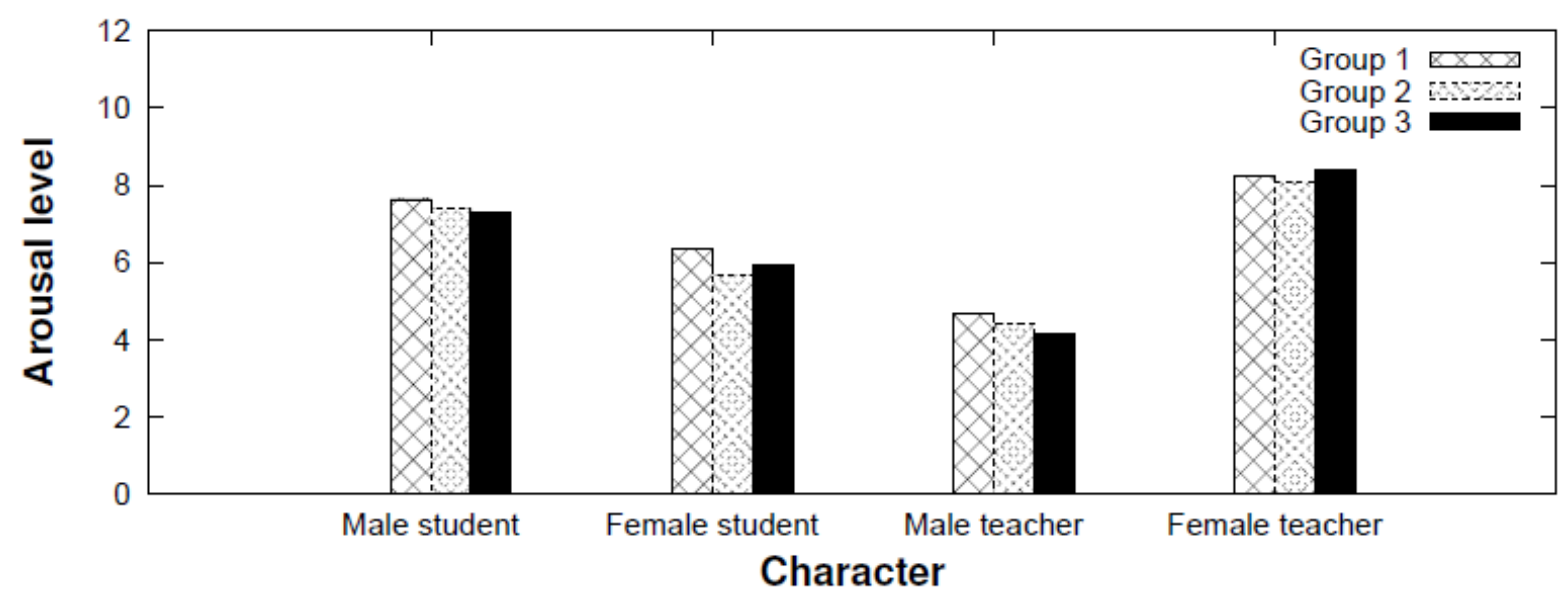

Figure 10. The mean value of the characters' stimulation levels.

Table 4. Comparison of the self-report method among the three groups

\begin{tabular}{ccccccc}
\hline Character & Source & SS & df & MS & $F$ & $p$-value \\
\hline Male & Between & 1.838 & 2 & 0.919 & 0.364 & 0.696 \\
student & Within & 204.65 & 81 & 2.527 & & \\
& Total & 206.488 & 83 & & & \\
\hline Female & Between & 11.494 & 2 & 5.747 & 1.795 & 0.173 \\
student & Within & 259.315 & 81 & 3.201 & & \\
& Total & 270.81 & 83 & & & \\
\hline Male & Between & 4.238 & 2 & 2.119 & 0.355 & 0.702 \\
teacher & Within & 483.437 & 81 & 5.968 & & \\
& Total & 487.676 & 83 & & & \\
\hline \multirow{2}{*}{ Female } & Between & 4.387 & 2 & 2.193 & 1.135 & 0.326 \\
teacher & Within & 156.506 & 81 & 1.932 & & \\
& Total & 160.893 & 83 & & & \\
\hline
\end{tabular}




\section{The effects of avatars' appearance in virtual Reality Drama}

Table 5. Comparison of the self-report method between males and females

\begin{tabular}{|c|c|c|c|c|c|c|c|}
\hline Character & Group & Sex & $n$ & $\mu$ & $\sigma$ & $t$ & $p$-value \\
\hline \multirow{6}{*}{$\begin{array}{l}\text { Male } \\
\text { student }\end{array}$} & \multirow{2}{*}{$\begin{array}{l}\text { Group1 } \\
(n=28)\end{array}$} & Male & 16 & 7.625 & 1.5864 & \multirow{2}{*}{-0.07} & \multirow{2}{*}{0.944} \\
\hline & & Female & 12 & 7.6667 & 1.49747 & & \\
\hline & \multirow{2}{*}{$\begin{array}{l}\text { Group2 } \\
(n=29)\end{array}$} & Male & 15 & 7.6667 & 1.1127 & \multirow{2}{*}{1.539} & \multirow{2}{*}{0.135} \\
\hline & & Female & 14 & 6.8929 & 1.57112 & & \\
\hline & \multirow{2}{*}{$\begin{array}{l}\text { Group3 } \\
(n=27)\end{array}$} & Male & 11 & 8.2727 & 1.67874 & \multirow{2}{*}{1.79} & \multirow{2}{*}{0.086} \\
\hline & & Female & 17 & 7.0313 & 1.83002 & & \\
\hline \multirow{6}{*}{$\begin{array}{l}\text { Female } \\
\text { student }\end{array}$} & \multirow{2}{*}{$\begin{array}{l}\text { Group1 } \\
(n=28)\end{array}$} & Male & 16 & 6.1875 & 1.32759 & \multirow{2}{*}{-0.664} & \multirow{2}{*}{0.512} \\
\hline & & Female & 12 & 6.5 & 1.08711 & & \\
\hline & \multirow{2}{*}{$\begin{array}{l}\text { Group2 } \\
(n=29)\end{array}$} & Male & 15 & 6.4667 & 1.72654 & \multirow{2}{*}{1.615} & \multirow{2}{*}{0.118} \\
\hline & & Female & 14 & 5.2857 & 2.1989 & & \\
\hline & \multirow{2}{*}{$\begin{array}{l}\text { Group3 } \\
(n=27)\end{array}$} & Male & 11 & 5.9091 & 1.446 & \multirow{2}{*}{1.082} & \multirow{2}{*}{0.29} \\
\hline & & Female & 17 & 5.0625 & 2.29401 & & \\
\hline \multirow{6}{*}{$\begin{array}{l}\text { Male } \\
\text { teacher }\end{array}$} & \multirow{2}{*}{$\begin{array}{l}\text { Group1 } \\
(n=28)\end{array}$} & Male & 16 & 5.0313 & 2.63609 & \multirow{2}{*}{1.262} & \multirow{2}{*}{0.218} \\
\hline & & Female & 12 & 3.9167 & 1.78164 & & \\
\hline & \multirow{2}{*}{$\begin{array}{l}\text { Group2 } \\
(n=29)\end{array}$} & Male & 15 & 4.8 & 2.33605 & \multirow{2}{*}{1.386} & \multirow{2}{*}{0.177} \\
\hline & & Female & 14 & 3.5 & 2.71038 & & \\
\hline & \multirow{2}{*}{$\begin{array}{l}\text { Group3 } \\
(n=27)\end{array}$} & Male & 11 & 4.7273 & 2.61116 & \multirow{2}{*}{0.041} & \multirow{2}{*}{0.967} \\
\hline & & Female & 17 & 4.6875 & 2.3585 & & \\
\hline \multirow{6}{*}{$\begin{array}{l}\text { Female } \\
\text { teacher }\end{array}$} & \multirow{2}{*}{$\begin{array}{l}\text { Group1 } \\
(n=28)\end{array}$} & Male & 16 & 8 & 1.08012 & \multirow{2}{*}{-0.953} & 0.349 \\
\hline & & Female & 12 & 8.4583 & 1.46874 & & 0.349 \\
\hline & Group2 & Male & 15 & 8.1333 & 1.80739 & 0.207 & 0838 \\
\hline & $(n=29)$ & Female & 14 & 8.25 & 1.12233 & & \\
\hline & Group3 & Male & 11 & 8 & 1.48324 & 0.903 & 0.375 \\
\hline & $(n=27)$ & Female & 17 & 7.5 & 1.36626 & 0.903 & 0.375 \\
\hline
\end{tabular}

\subsection{Analysis of the Groups' Change through R-R Intervals}

Figure 11 shows the difference in the mean value of R-R intervals among the three groups $(* \mathrm{p}<.05, * * * \mathrm{p}<.001)$. Figure 12 shows a time-series plot per second of the change in the mean value of R-R intervals within the groups while watching Scene 1 (a 62-second video clip on a conflict between a male teacher and a female student). As a result of conducting repeated measures ANOVAs in order to analyse the difference among the groups, the between-subject effects of R-R intervals were not significant $\left(F[2,4941]=2.872, p=.062, \eta^{2}=.066\right)$. Based on a p-value below 0.05 , there was no significant difference, but considering the eta squared there was about a medium-sized effect. There was a slight tendency for the viewers' R-R intervals to narrow as the size of a shot got smaller. The interactions between the time and group of effects were not significant $\left(F[2,4941]=.676, p=.997, \eta^{2}=.016\right)$. This implied that there was no difference in the pattern of the change in R-R intervals among the groups according to the passage of time. The within-subject effects were not significant $\left(F[2,4941]=.707, p=.959, \eta^{2}\right.$ $=.009$ ). This showed that there was no difference in the pattern of the changes in R-R intervals 


\section{The effects of avatars' appearance in virtual Reality Drama}

within the groups according to the passage of time.

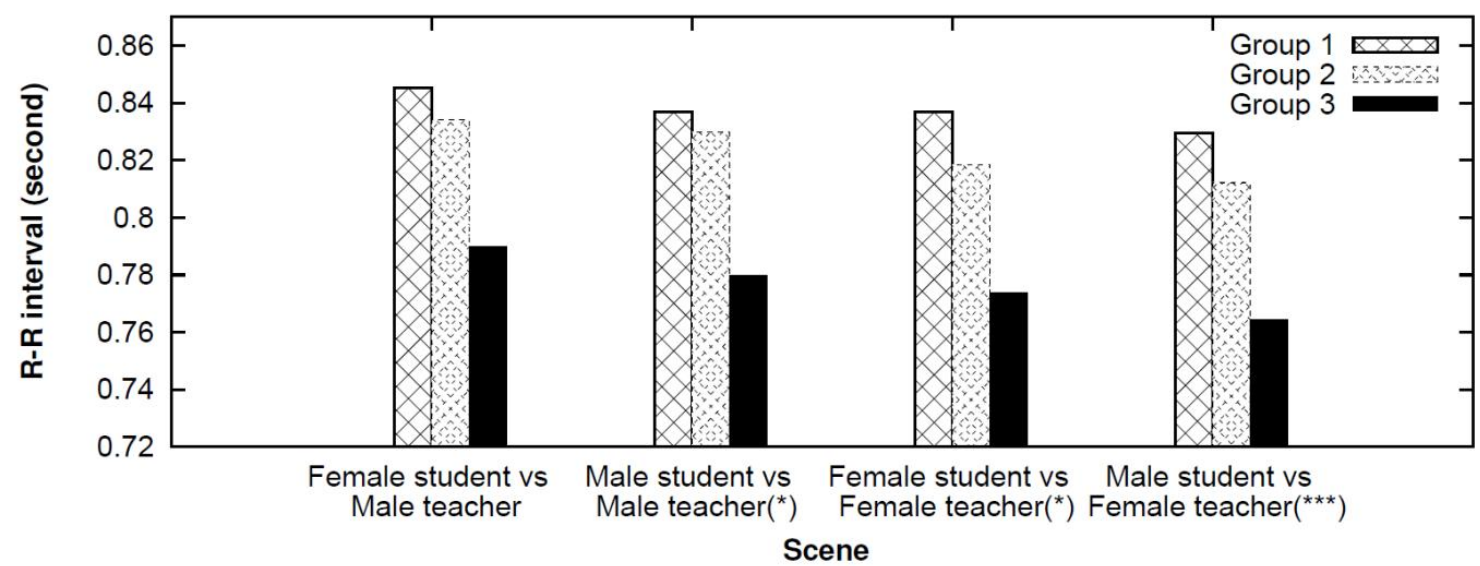

Figure 11. The mean value of R-R intervals (among three groups). $* \mathrm{p}<.05, * * \mathrm{p}<.01, * * * \mathrm{p}<.001$

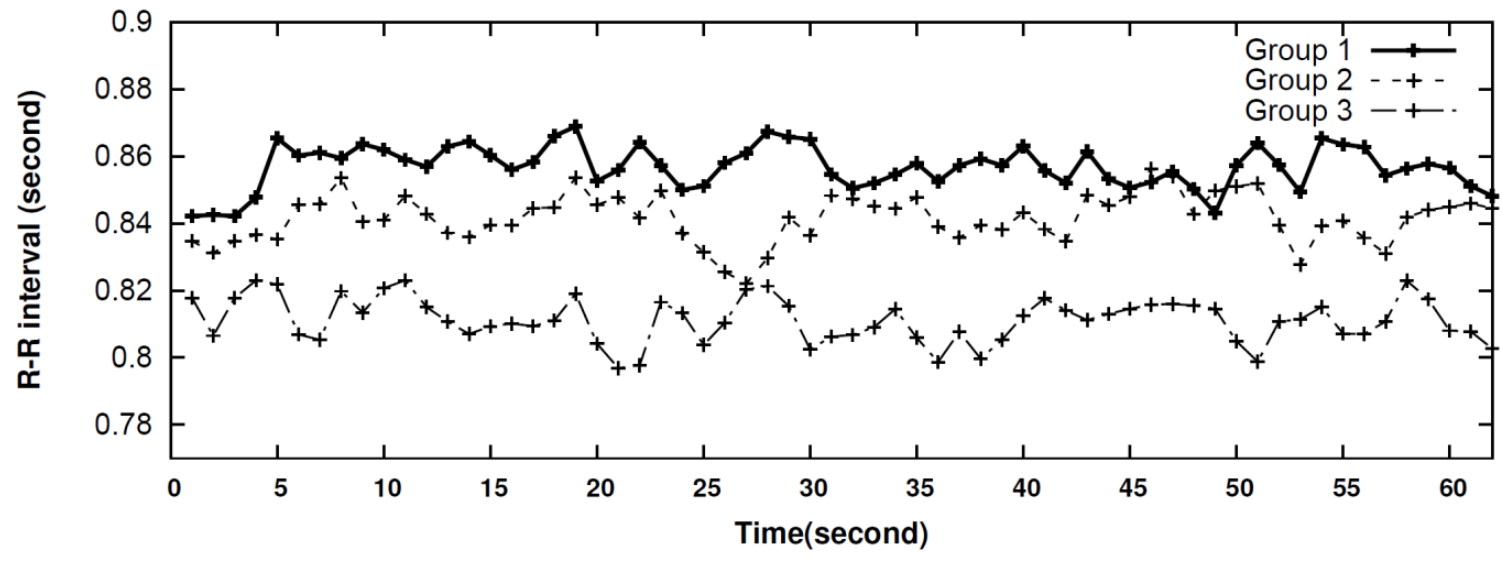

Figure12. R-R interval profile - scene 1 (Female student vs. Male teacher).

Figure 13 shows a time-series plot per second of the change in the mean value of R-R intervals within the groups while watching Scene 2 (a 41-second video clip on a conflict between a male student and a male teacher). As a result of conducting repeated measure ANOVAs in order to analyse the difference among the groups, one can see that the between-subject effect of R-R intervals was significant $\left(\mathrm{F}[2,3240]=3.451, \mathrm{p}=.036, \eta^{2}=.079\right)$. There was a tendency for the viewers' R-R interval to narrow as the size of a shot got smaller, and there was about a mediumsized effect. The interactions between the time and group of effect were significant $(F[2,3240]=$ $\left.1.656, p=.000, \eta^{2}=.039\right)$. As a result of conducting a t-test revising significance levels by using Bonferroni's method to check at what point in time the interactions took place, the difference between Group 2 and Group 3 became similar after 20 seconds. The result from Group 1 after 20 
seconds resembled that of Group 2 because of the male student's line that revealed his dramatic resistance towards the male teacher. The within-subject effects were not significant $(F[2,3240]$ $\left.=.722, \mathrm{p}=.903, \eta^{2}=.009\right)$.

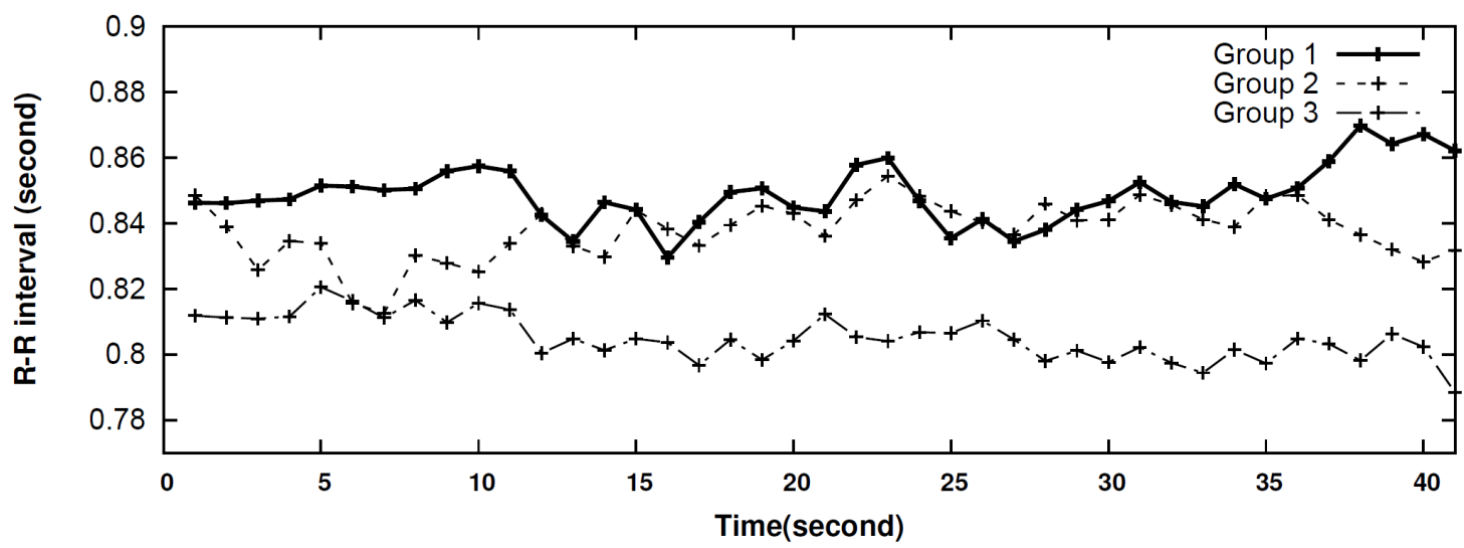

Figure 13. R-R interval profile - scene 2 (Male student vs. Male teacher).

Figure 14 shows a partial time-series plot per second of the change in the mean value of R-R intervals within the groups while watching Scene 3 (a 95-second video clip on a conflict between a male student and a female teacher). As a result of conducting repeated measure ANOVAs in order to analyse the difference among the groups, the between-subject effect of the R-R intervals was significant $\left(F[2,7614]=3.834, p=.026, \eta^{2}=.086\right)$. However, the interactions between the time and group of effects were not significant $\left(F[2,7614]=1.009, p=.454, \eta^{2}=.024\right)$ along with the within-subject effects $\left(F[2,7614]=1.086, p=.268, \eta^{2}=.013\right)$.

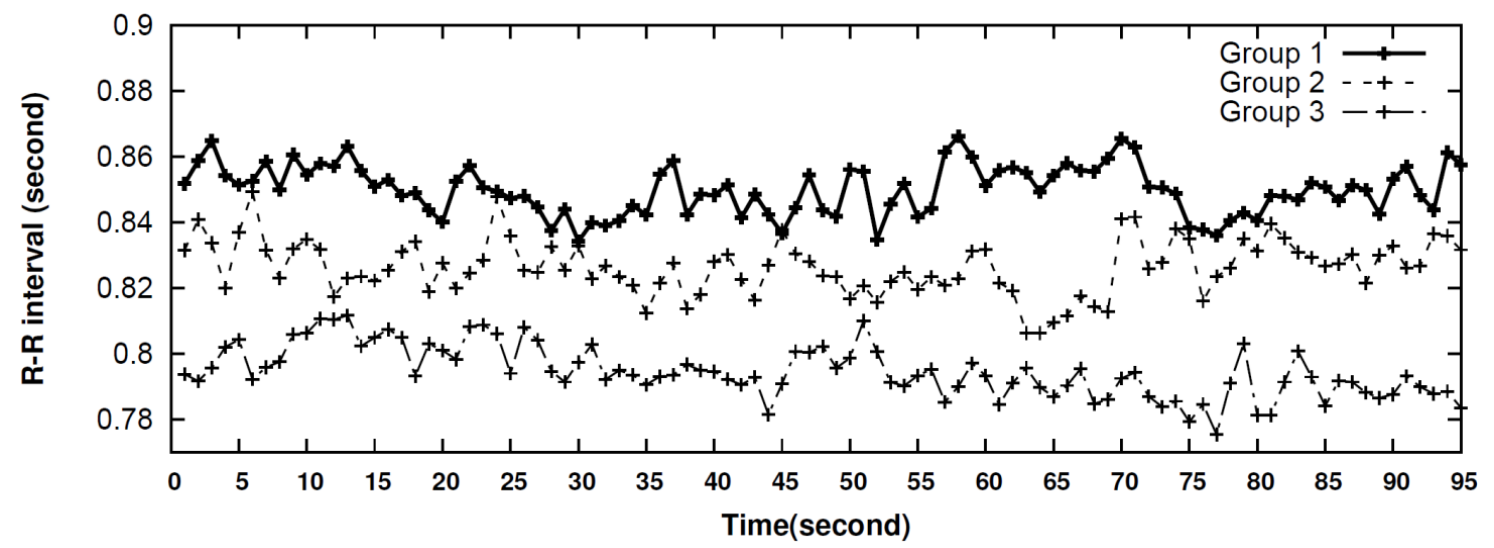

Figure 14. R-R interval profile - scene 3 (Female student vs. Female teacher). 


\section{The effects of avatars' appearance in virtual Reality Drama}

Figure 15 shows a partial time-series plot per second of the change in the mean value of R-R intervals within the groups while watching Scene 4 (a 53-second video clip on a conflict between a female student and a female teacher). As a result of conducting repeated measure ANOVAs in order to analyse the difference among the groups, the between-subject effect of R-R interval was significant $\left(\mathrm{F}[2,4212]=4.254, \mathrm{p}=.000, \eta^{2}=.095\right)$, but the interactions between the time and group of effects were not significant $\left(F[2,4212]=.755, p=.970, \eta^{2}=.018\right)$. The within-subject effects were not significant as well $\left(\mathrm{F}[2,4212]=1.472, \mathrm{p}=.016, \eta^{2}=0.018\right)$.

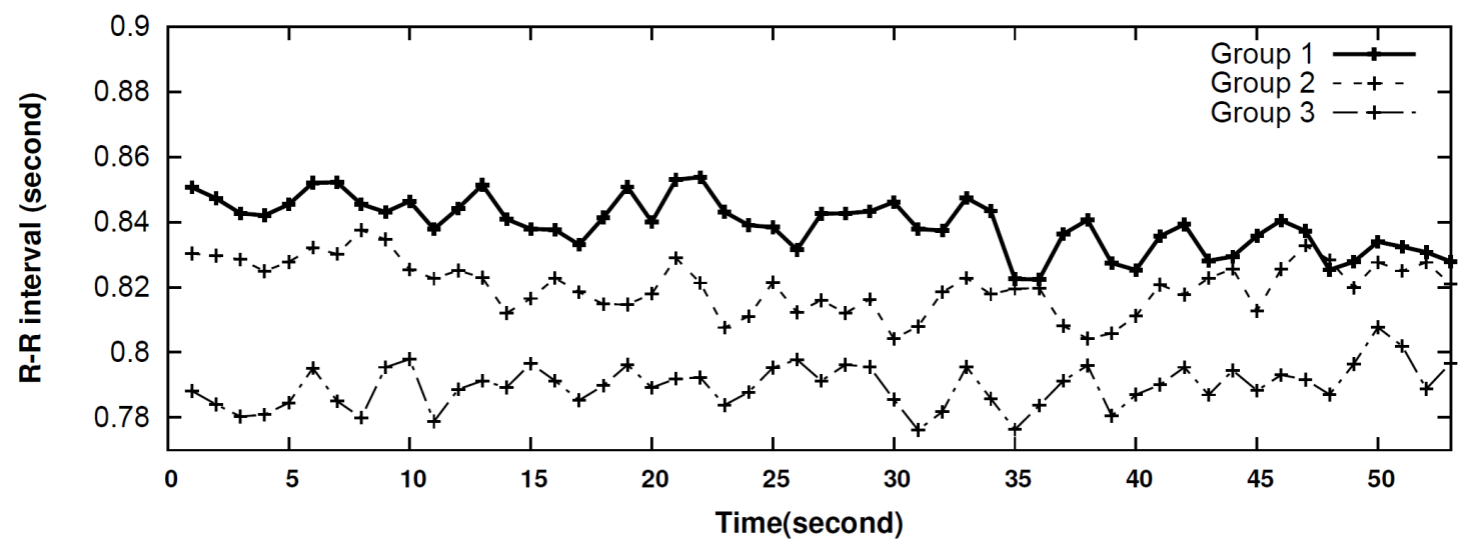

Figure 15. R-R interval profile - scene 4 (Male student vs. Female teacher).

The difference in gender within the group was significant in Group 3 watching Scenes 2 and 3 (Table 6). Due to the conflicts between a male student and a male teacher and between a female student and a female teacher, the female subjects' levels of stimulation became intense $(\mu=$ $0.7378, \sigma=0.07944 ; \mu=0.7376, \sigma=0.07862$ ). 


\section{The effects of avatars' appearance in virtual Reality Drama}

Table 6. Comparison of the mean value of R-R intervals (between males and females)

\begin{tabular}{|c|c|c|c|c|c|c|c|}
\hline Scene & Group & Sex & $n$ & $\mu$ & $\sigma$ & $t$ & $p$-value \\
\hline \multirow{6}{*}{$\begin{array}{l}\text { Female } \\
\text { student } \\
\text { vs. } \\
\text { Male } \\
\text { teacher }\end{array}$} & \multirow{2}{*}{$\begin{array}{l}\text { Group1 } \\
(n=28)\end{array}$} & Male & 16 & 0.8531 & 0.0853 & \multirow{2}{*}{0.671} & \multirow{2}{*}{0.508} \\
\hline & & Female & 12 & 0.8349 & 0.06818 & & \\
\hline & \multirow{2}{*}{$\begin{array}{l}\text { Group1 } \\
(n=29)\end{array}$} & Male & 15 & 0.8293 & 0.09752 & \multirow{2}{*}{-0.293} & \multirow{2}{*}{0.772} \\
\hline & & Female & 14 & 0.8392 & 0.08307 & & \\
\hline & \multirow{2}{*}{$\begin{array}{l}\text { Group1 } \\
(n=27)\end{array}$} & Male & 11 & 0.8412 & 0.12143 & \multirow{2}{*}{2.121} & \multirow{2}{*}{0.051} \\
\hline & & Female & 17 & 0.7542 & 0.0739 & & \\
\hline \multirow{6}{*}{$\begin{array}{l}\text { Male } \\
\text { student vs. } \\
\text { Male } \\
\text { teacher }\end{array}$} & \multirow{2}{*}{$\begin{array}{l}\text { Group1 } \\
(n=28)\end{array}$} & Male & 16 & 0.8416 & 0.07904 & \multirow{2}{*}{0.405} & \multirow{2}{*}{0.689} \\
\hline & & Female & 12 & 0.8306 & 0.05827 & & \\
\hline & \multirow{2}{*}{$\begin{array}{l}\text { Group1 } \\
(n=29)\end{array}$} & Male & 15 & 0.8292 & 0.09427 & \multirow{2}{*}{-0.032} & \multirow{2}{*}{0.975} \\
\hline & & Female & 14 & 0.8302 & 0.07308 & & \\
\hline & \multirow{2}{*}{$\begin{array}{l}\text { Group1 } \\
(n=27)\end{array}$} & Male & 11 & 0.8406 & 0.11109 & \multirow{2}{*}{2.813} & \multirow{2}{*}{$0.009^{* *}$} \\
\hline & & Female & 17 & 0.7378 & 0.07944 & & \\
\hline \multirow{6}{*}{$\begin{array}{l}\text { Female } \\
\text { student } \\
\text { vs. } \\
\text { Female } \\
\text { teacher }\end{array}$} & \multirow{2}{*}{$\begin{array}{l}\text { Group1 } \\
(n=28)\end{array}$} & Male & 16 & 0.8444 & 0.0744 & \multirow{2}{*}{0.706} & \multirow{2}{*}{0.487} \\
\hline & & Female & 12 & 0.8267 & 0.05113 & & \\
\hline & \multirow{2}{*}{$\begin{array}{l}\text { Group1 } \\
(n=29)\end{array}$} & Male & 15 & 0.816 & 0.09153 & \multirow{2}{*}{-0.155} & \multirow{2}{*}{0.878} \\
\hline & & Female & 14 & 0.821 & 0.08206 & & \\
\hline & \multirow{2}{*}{$\begin{array}{l}\text { Group1 } \\
(n=27)\end{array}$} & Male & 11 & 0.8261 & 0.11987 & \multirow{2}{*}{2.325} & \multirow{2}{*}{$0.028^{*}$} \\
\hline & & Female & 17 & 0.7376 & 0.07862 & & \\
\hline \multirow{6}{*}{$\begin{array}{l}\text { Male } \\
\text { student } \\
\text { vs. } \\
\text { Female } \\
\text { teacher }\end{array}$} & \multirow{2}{*}{$\begin{array}{l}\text { Group1 } \\
(n=28)\end{array}$} & Male & 16 & 0.8351 & 0.07537 & \multirow{2}{*}{0.524} & 0.605 \\
\hline & & Female & 12 & 0.8218 & 0.05206 & & \\
\hline & Group1 & Male & 15 & 0.8187 & 0.09055 & 0.439 & 0.664 \\
\hline & $(n=29)$ & Female & 14 & 0.8051 & 0.07559 & 0.4 .59 & 0.004 \\
\hline & Group1 & Male & 11 & 0.8032 & 0.12584 & 1678 & 0.106 \\
\hline & $(n=27)$ & Female & 17 & 0.7374 & 0.07843 & & \\
\hline
\end{tabular}

\section{Discussion and Conclusion}

Recently, virtual reality classrooms and virtual reality drama have been used for E-learning and teacher training. Education students are able to hone their skills in front of almost life-like students $(\mathrm{Hu}$ (2016)). The situations in virtual reality classrooms could provide the teachers with the situated teaching method.

This study confirms how viewers perceived the same scenes filmed with different shot sizes. As a result of providing the same virtual reality drama scenes with different shot sizes to three different groups, changes in the ANS corresponding to changes in the shot size were found to be highly relevant. Except for Scene 1, the between-subject effects were significant. One can conclude that as the size of the shot decreased, the viewers' R-R intervals in the ECGs tended to get narrower. This result strongly supports Hypothesis 1, which states that the response of a viewer's ANS would be significantly different according to the size of the shot. As this result differed from the self-reporting method measured on the 10-point scale, Hypothesis 2, which 


\section{The effects of avatars' appearance in virtual Reality Drama}

states that the self-reporting method on viewers' level of stimulation and the methods of the ANS function test would show a difference, is clearly proven. The testing of physiological reactions was more appropriate to studying the viewers' levels of stimulation than the verbal reports, as there were less cultural differences and it was less affected by reasonable judgment.

The difference in gender within each group was statistically significant only in Group 3, who saw the scenes filmed in close-up. The results showed that the female participants tended to absorb the characters' emotions more than the male participants when the psychological distance reached the close-up shots. Therefore, Hypothesis 3, which stated that the response in viewers' ANS would vary from male to female according to shot size, should be dismissed. This also implies that the size of a shot was more important than the content of the video based on gender.

For all the scenes, the within-subject effects were not significant. This showed that there was no difference in the R-R interval change pattern within the groups over time. Except for Scene 2, the interaction between time and group was not significant. From this, we can also conclude that there was no difference in the R-R interval change patterns within the groups over time. Therefore, Hypothesis 4, which states that the response of the ANS would be different according to the scenes in a virtual reality drama, should be dismissed. This also implies that shot size was more important than the content of the video.

As shot size decreased, the R-R intervals in the ECGs tended to get narrower. It was observed statistically that the R-R intervals in the ECGs tended to get wider as the shot size increased. This result also implies that shot size is proportional to the viewers' psychological distance for recognizing it. As the shot size got narrower, the psychological distance between the viewer and the characters got closer, and vice versa.

The concept of distance used in various academic fields refers to aesthetic distance in aesthetics and psychical distance in theories of fiction. The aesthetic distance means effectively controlling the subject's view on the object (Sherburne (1961)). In other words, it is related to how far the distance has to be for the object's substance to be revealed (Bullough (1912)). In novels, the distance refers to the author's psychical or emotional distance from the object (Booth (1961)). The author may be more or less distant from the character. As in novels, various methods are used in virtual reality drama to adjust the distance between the characters and the viewers. This study proves that, based on their bio-signal measurements, there is a change in viewers' perception depending on the size of the shot. 
The method evaluating the participants' levels of stimulation after watching the video clips did not show differences among the groups, but the real-time bio-signal measurements while watching the scenes were statistically significant. The difference in this work compared with previous studies is that it provides visualizations of objective data using ECG recordings. The analysis of R-R intervals could be regarded as a method of neurocommunication, similar to neurocinematics, which analyses the viewers' state of mind as it instantly monitors dynamic emotional states (Hasson (2008)). ${ }^{2}$

So far, video clip editing has been under the director's autonomy. However, if editing is to immerse the audience in the natural narrative, it needs to adopt technology which analyzes the viewer's psychological distance according to changes in the audience's ANS and reflects it in the edit. The concept of psychological distance used in various academic fields refers to aesthetic distance in aesthetics and psychical distance in theories of fiction. The smaller the shot size, the greater the level of identification between audience and actor. For the same size shot, the overthe shoulder shot maintains the psychical distance between characters and viewers to a certain degree. This tells us which characters are most important in a scene or at a particular point in the narrative. The set of scales defined in this study is as follows Figure 16:

The size of a shot

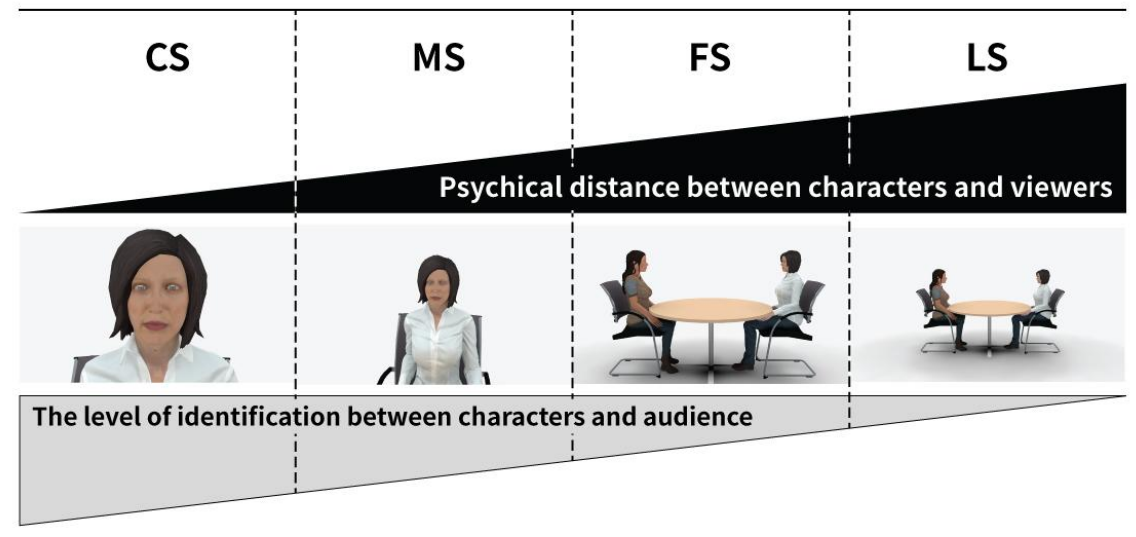

Figure 16. Association between the size of a shot and audience participation

This study has several limitations. First, the number of participants was small. More samples

\footnotetext{
${ }^{2}$ Neurocommunication research uses technologies such as functional magnetic resonance imaging (fMRI) to measure changes in activity in parts of the brain, electroencephalography (EEG) to measure activity in specific regional spectra of brain response, and/or sensors to measure changes in viewers' physiological states to learn exactly what message excites or disinterests the viewer.
} 


\section{The effects of avatars' appearance in virtual Reality Drama}

were needed in order to reach a conclusion regarding gender difference in accommodating the video (Angelini (2008)). This would have made it possible to offer generalizations. Additionally, further research applying this method to various scenes that do not involve conversations is required. For example, results from similar studies with scenes using the "charade method," not conversational scenes, should be examined.

In conclusion, as the psychical distance between the viewers and virtual reality drama characters was related to shot size, and producers could control the psychical distance by adjusting the shot size.

\section{Disclosure statement}

No potential conflict of interest was reported by the authors.

\section{Funding}

This work was supported by the Incheon National University Research Grant in 2014.

\section{References}

Andreoni, G., Anisetti, M., Apolloni, B., Bellandi, V., Balzarotti, S., Beverina, F., Campadelli, P., Ciceri, M. R., Colombo, P., Fumagalli, F., Palmas, G., Piccini, L. 2006. "Emotional interfaces with ambient intelligence." Ambient Intelligence, Wireless Networking and Ubiquitous Computing, Athanasios Vasilakos and Witold Pedycz, Artech House, USA.

Anisetti, M., Bellandi, V. 2009. "Emotional State Inference Using Face Related Features.” New Directions in Intelligent Interactive Multimedia Systems and Services - 2, Chapter 37, 226: $401-411$.

Andrea D., Francese. R., Passero. L., Tortora. G. 2009. "Development and Evaluation of a Virtual Campus on Second Life: The Case of Second DMI." Computers \& Education, 52 (1): 220-233.

Angelini, J. R. 2008. Television Sports and Athlete Sex: Looking at the Differences in Watching Male and Female Athletes. Journal of Broadcasting \& Electronic Media, 52 (1): 16-32. Arijon, D. 1976. Grammar of the Film Language. London: Focal Press.

Banakou, D., Chorianopoulos, k. 2010. "The effects of Avatars' Gender and Appearance on Social Behavior in Online 3D Virtual Worlds." Journal of Virtual Worlds Research, 2 


\section{The effects of avatars' appearance in virtual Reality Drama}

(5).

Barlow, D. H. 2001. Anxiety and Its Disorders: The Nature and Treatment of Anxiety and Panic. NY: Guilford Press.

Berntson, G. G., Bigger, J. T. Jr., Eckberg, D. L., Grossman, P., Kaufmann, P. G., Malik, M., Nagaraja, H. N., et al. 1997. "Heart rate variability: Origins, methods, and interpretive caveats." Psychophysiology, 34: 623-648.

Bordwell, D. and Kristin T. 1993. Film Art: An Introduction. New York: McGraw Hill.

Bullough, E. 1912. "Psychical Distance as a factor in Art and an Aesthetic Principle. British." Journal of Psychology, 5: 87-118.

Dillard, J. P., and Wilson, B. J. 1993. "Communication and effect." Communication Research, 20: 637-646.

Ekman, P., and Erika L. R. 1997. "What the face reveals: Basic and applied studies of spontaneous expression using the Facial Action Coding System (FACS)." Oxford University Press.

Fox, S. I. 2008. Human physiology. McGraw-Hill College.

Ghanem, K., and Caplier, A. 2013. “Towards a full emotional system.” Behaviour \& Information Technology, 32(8): 783-799.

Garcia, T. B. and Holtz, N. E. 2011. Introduction to 12-lead ECG: The art of interpretation. Jones \& Bartlett Publishers.

Gerber, G. L., and Kasman, J. 1971. "Expression of emotion through family grouping schemata, distance, and interpersonal focus." Journal of Consulting and Clinical Psychology, 36: 370-377.

Hasson, U., Landersman, O., Knappmeyer, B., Vallines, I., Rubin, N., and Heeger, D. J. 2008. "Neurocinematics: The Neuroscience of Film." Projections 2 (1): 1-26.

Hu, R.,Wu, Y. Y. and Shieh, C. J. 2016. "Effects of Virtual Reality Integrated Creative Thinking Instruction on Students' Creative Thinking Abilities." EURASIA Journal of Mathematics, Science and Technology, 12(2): 477-486

Kipper, P. 1986. “Television camera movement as a source of perceptual information.” Journal of Broadcasting \& Electronic Media, 30: 295-307.

Lang, A., Dhillon, K. and Dong, Q. 1995. "Effects of Emotional Arousal and Valence on Television Viewers' Cognitive Capacity and Memory." Journal of Broadcasting \& 


\section{The effects of avatars' appearance in virtual Reality Drama}

Electronic Media, 39 (3): 313-327.

Lang, A., Shin, M., Bradley, S. D., Wang, Z., Lee, S. and Potter, D. 2005. "Wait! Don't turn that dial! More excitement to come! The effects of story length and production pacing in local television news on channel changing behavior and information processing in a free choice environment." Journal of Broadcasting \& Electronic Media, 49: 3-22.

Lang, A., Zhou, S., Schwartz, N. and Bolls, P. D. 2000. "Effects of Edits on Arousal, Attention, and Memory for Television Messages: When an Edit Is an Edit Can an Edit Be too Much.” Journal of Broadcasting \& Electronic Media 44 (1): 94-109.

Lee, E. J. 2004. "Effects of visual representation on social influence in computer-mediated communication: Experimental tests of the social identity model of deindividuation effects." Human Communication Research, 30: 234-259.

Mattes, J. and Cantor, J. 1982. "Enhancing Responses to Television Advertisements via the Transfer of Residual Arousal from Prior Programming." Journal of Broadcasting \& Electronic Media 26 (2): 553-566.

Millerson, G. 1985. The Technique of Television Production. London: Focal Press.

Monaco, J. 1981. How to Read a Film. New York: Oxford University Press.

Rada, J. A. and Wulfemeyer, K. T. 2005. "Color coded: Racial descriptors in television coverage of intercollegiate sports". Journal of Broadcasting \& Electronic Media 49: 65-85.

Ravaja, N. 2004. "Effects of image motion on a small screen on emotion, attention, and memory: Moving-face versus static-face newscaster." Journal of Broadcasting \& Electronic Media 48: 108-133.

Sherburne, D. 1961. A Whiteheadean Aesthetic. New York: Yale.

Simons, R. F., Detenber, B. H., Reiss, J. E., and Shults, C. W. (2000). "Image motion and context: A between- and within-subjects comparison." Psychophysiology 37: 706-710.

Sinji, M. 2004. Comfortable engineering. (trans: Min., B. C.). Sigma press. Walma van der Molen, J. H., and Klijn, M. E. 2004. "Recall of television versus print news: Retesting the semantic overlap hypothesis." Journal of Broadcasting \& Electronic Media, 48: 89107.

Wayne C. Booth, 1961. The Rhetoric of Fiction. Chicago: University of Chicago Press.

Yang, H. K., Lee, J. W., Lee, Y. J., Kim, K. S., Lee, K. H., and Choi, H. J. 2009. "HRV Evaluation under Stress Condition by Using Patch Type Bipolar Heart Activity 
Monitoring System." Journal of Korean Society for emotion and sensibility, 12 (2): 161-168.

Zettle, H. 1998. Sight, Sound, Motion: Applied Media Aesthetics (3rd ed.). Belmont, CA: Wadsworth. 


\section{Appendix \\ Scripts of the Virtual Reality drama Clips Used as Stimulus Materials}

S\# 1 Conflict between a female student and a male teacher about the teacher's academic guidance

\begin{tabular}{|c|c|c|c|}
\hline \multicolumn{3}{|c|}{ Source } & \multirow{2}{*}{ Script } \\
\hline 1 & 2 & 3 & \\
\hline \multirow{6}{*}{ 2S FS } & \multicolumn{2}{|c|}{$2 \mathrm{~S} F S$} & Student hesitates then walks up to the teacher \\
\hline & 1S WS & $1 \mathrm{~S}$ CS & $\begin{array}{l}\text { T: What? } \\
\text { S: Can I sign up for it now? The essay exam. I mean. }\end{array}$ \\
\hline & 1S BS & $1 \mathrm{~S}$ CS & $\begin{array}{l}\text { T: You can, but for what? Use that time to study more for the entrance exam. } \\
\text { S: But you told me that it's unlikely my score will improve. So then I should at least try to } \\
\text { get more specs. }\end{array}$ \\
\hline & $1 \mathrm{~S}$ CS & $1 \mathrm{~S}$ CS & $\begin{array}{l}\text { T: If you were thinking of doing that, you should have started preparing for it from first } \\
\text { grade. Preparing specs according to the department you will apply to. } \\
\text { S: How? }\end{array}$ \\
\hline & $1 \mathrm{~S} \mathrm{CU}$ & $1 \mathrm{~S} \mathrm{CS}$ & $\begin{array}{l}\text { T: That's what everyone else does. } \\
\text { S: How can one decide everything in first grade? Did you know for certain what you were } \\
\text { going to do in your first grade? I didn't have any thoughts on university until last year, so } \\
\text { how am I supposed to decide on my future? }\end{array}$ \\
\hline & $\begin{array}{l}1 \mathrm{~S} \\
\mathrm{ECU}\end{array}$ & $1 \mathrm{~S} \mathrm{CS}$ & $\begin{array}{l}\text { T: That's why this is so difficult. } \\
\text { S: (angry) }\end{array}$ \\
\hline
\end{tabular}

S\# 2 Conflict between a male student and a male teacher about the teacher's school guidance

\begin{tabular}{|c|c|c|c|}
\hline \multicolumn{3}{|c|}{ Source } & \multirow{2}{*}{ Script } \\
\hline 1 & 2 & 3 & \\
\hline \multirow{6}{*}{ 2S FS } & \multicolumn{2}{|c|}{$2 \mathrm{~S} \mathrm{FS}$} & Student and teacher stare at each other \\
\hline & $1 \mathrm{~S}$ WS & $1 \mathrm{~S} \mathrm{CS}$ & $\begin{array}{l}\text { T: It's you, isn't it? } \\
\text { S: No it's not. }\end{array}$ \\
\hline & 1S BS & $1 \mathrm{~S} \mathrm{CS}$ & $\begin{array}{l}\text { T: This picture, isn't this you? I'll give you } 20 \text { minutes to write a statement. } \\
\text { S: But I have nothing to write. It's not me. }\end{array}$ \\
\hline & 1S CS & 1S CS & $\begin{array}{l}\text { T: Grab your pen and start writing. } \\
\text { S: And if I don't? What would you do if I don't? }\end{array}$ \\
\hline & $1 \mathrm{~S} \mathrm{CU}$ & 1S CS & $\begin{array}{l}\text { T: You... I'm calling your parents. } \\
\text { S: What? Just hit me instead. }\end{array}$ \\
\hline & $\begin{array}{l}1 \mathrm{~S} \\
\mathrm{ECU}\end{array}$ & 1S CS & $\begin{array}{l}\text { T: What did you just say? } \\
\text { S: (angry) }\end{array}$ \\
\hline
\end{tabular}




\section{The effects of avatars' appearance in virtual Reality Drama}

S\# 3 Conflict between a female student and a female teacher about the teacher's academic guidance

\begin{tabular}{|c|c|c|c|}
\hline \multicolumn{3}{|c|}{ Source } & \multirow{2}{*}{ Script } \\
\hline 1 & 2 & 3 & \\
\hline \multirow{6}{*}{$2 \mathrm{~S} F \mathrm{~F}$} & \multicolumn{2}{|c|}{ 2S FS } & Student walks up to the teacher \\
\hline & 1S WS & $1 \mathrm{~S} \mathrm{CS}$ & $\begin{array}{l}\text { S: Teacher. } \\
\text { T: Yes? }\end{array}$ \\
\hline & 1S BS & $1 \mathrm{~S} \mathrm{CS}$ & $\begin{array}{l}\text { S: I think you made a mistake on my score. } \\
\text { T: Let's see. No, I don't see anything wrong. }\end{array}$ \\
\hline & 1S TBS & $1 \mathrm{~S} \mathrm{CS}$ & $\begin{array}{l}\text { S: Introduction, statement, evidence, and conclusion are all there. } \\
\mathrm{T} \text { : An essay is to write your own thoughts, but your opinion isn't here. }\end{array}$ \\
\hline & 1S CU & $1 \mathrm{~S}$ CS & $\begin{array}{l}\text { S: I want another teacher to score my essay. } \\
\text { T: No, this is your final score. I can't give you points for writing just like the sample answer. }\end{array}$ \\
\hline & $\begin{array}{l}\text { IS } \\
\text { ECU }\end{array}$ & $1 \mathrm{~S} \mathrm{CS}$ & $\begin{array}{l}\text { S: Then what is the sample answer for? } \\
\text { T: (dumbfounded) }\end{array}$ \\
\hline
\end{tabular}

S\# 4 Conflict between a male student and a female teacher about the teacher's school guidance

\begin{tabular}{|c|c|c|c|}
\hline \multicolumn{3}{|c|}{ Source } & \multirow{2}{*}{ Script } \\
\hline 1 & 2 & 3 & \\
\hline \multirow{5}{*}{$2 \mathrm{~S} \mathrm{FS}$} & 1S WS & $1 \mathrm{~S} \mathrm{CS}$ & $\begin{array}{l}\text { T: Jinwoong, you're short of in-school volunteer work and too much absence. You might } \\
\text { not be able to graduate. Do you want to graduate? Is there anything troubling you? Any } \\
\text { problems at home? } \\
\text { S: Why do you care? }\end{array}$ \\
\hline & 1S BS & $1 \mathrm{~S} \mathrm{CS}$ & $\begin{array}{l}\text { T: I am curious. } \\
\text { S: So what if there's something going on? What can you possibly do for me? I have things } \\
\text { to do, so don't bother to call to me again for these kinds of issues. }\end{array}$ \\
\hline & 1S TBS & $1 \mathrm{~S} C \mathrm{~S}$ & $\begin{array}{l}\text { T: Jinwoong, wait. } \\
\text { S: Teacher, don't put a good face on. }\end{array}$ \\
\hline & 1S CS & $1 \mathrm{~S} \mathrm{CS}$ & $\begin{array}{l}\text { T: Jinwoong! } \\
\text { S: You don't have to act like you care. }\end{array}$ \\
\hline & $1 \mathrm{~S} \mathrm{CU}$ & $1 \mathrm{~S} \mathrm{CS}$ & $\begin{array}{l}\text { T: I'm not finished yet. } \\
\text { S: So what? What should I do then? }\end{array}$ \\
\hline
\end{tabular}

